\title{
Estrutura do mercado de trabalho metropolitano na Região Sul do Brasil, em 1995 e em 2005
}

\section{Palauras-chave}

desemprego, multinomial logit, transição no mercado de trabalho.

Classificação JEL C31, J21, $\mathrm{J} 82$.

\section{Key words}

labor dynamics, labor force participation, multinomial logit

JEL Classification C31, J21,

J82.

\section{Resumo}

Para melhor compreender as transições que ocorrem no mercado de trabalho, é importante considerar os fluxos de estar empregado, desempregado e fora do mercado de trabalho e as probabilidades envolvidas em função de variáveis socioeconômicas e geográficas. $\mathrm{O}$ modelo econométrico utilizado foi o multinomial logit, em que se observou que há diferença de gênero com respeito a estar ocupado e fora do mercado de trabalho, sendo que, para a primeira situação, a probabilidade é maior para o homem e, para a segunda situação, é menor. Verificou-se ainda relação positiva e decrescente entre idade e probabilidade de estar ocupado e relação negativa e decrescente entre idade e possibilidade de estar fora do mercado de trabalho. No que diz respeito à escolaridade, foi encontrada relação positiva sobre a probabilidade de estar ocupado. Ao comparar os anos de 1995 e 2005, verifica-se que a chance de estar desempregado foi maior em 2005. \\ Prof. adjunto do Departamento de Economia - UFPR
}

\section{Abstract}

To better understand transitions that took place in the labor market, it is important to consider the flows of being employed, unemployed and outside the labor market, and the probabilities involved, as a function of socioeconomic and geographical variables. The econometric model used was the multinomial logit model, which found that there is a gender difference in regards to being employed and outside the labor market.

For the first instance, the probability is greater for men, and for the second situation, it is lower. A positive and decreasing relationship was also found between age and the probability of being employed, and a negative and decreasing relationship between age and the probability of being outside the labor market. With regards to education level, a positive relationship was found with the probability of being employed. When comparing 1995 and 2005 , the probability of being unemployed in 2005 was found to be higher. 


\section{1_Introdução}

A característica do mercado de trabalho é altamente dinâmica, ocorrendo constantemente a entrada e a saída de pessoas. Existem fatores macroeconômicos, como a taxa de crescimento do país, a taxa de natalidade, a taxa de mortalidade, os choques tecnológicos, os choques externos, etc., que podem influenciar diretamente esse fluxo, bem como fatores microeconômicos como: idade, escolaridade, gênero, condição na família, região geográfica, entre outros. A reestruturação produtiva da economia iniciada na década de 90 envolveu uma massiva realocação do mercado de trabalho por meio da mudança de produtividade, do choque de demanda e da mudança na estrutura de incentivo como o valor do seguro-desemprego e sua duração.

A incidência desigual do desemprego entre regióes geográficas, como também entre diferentes grupos demográficos e socioeconômicos, pode levar a um desequilíbrio no mercado de trabalho, isto é, um aumento da demanda por trabalhadores qualificados por parte das empresas não cresce na mesma proporção que a disponibilidade de trabalhadores com tais qualificaçôes, fato que se mostra mais intenso em regiốes menos urbanizadas.
Nos últimos anos, a literatura aborda um aumento do emprego informal, a precarização dos empregos e a sensível redução no nível de emprego no setor industrial, o que leva a uma maior atenção na geração de emprego em outros setores da economia (Camargo, 1997). Esse fato pode ser visto de duas maneiras: como um problema essencialmente macroeconômico ao considerar a necessidade de acelerar o crescimento econômico a partir de instrumentos que controlem a demanda agregada, principalmente a taxa de juros e a política fiscal, e guiando-se pela necessidade de atuar diretamente sobre as variáveis no mercado de trabalho. Essas opçôes não são mutuamente exclusivas; pelo contrário, devem ser complementares.

As políticas voltadas para o mercado de trabalho podem ser classificadas em dois grupos. A primeira diz respeito ao grau de flexibilidade do mercado de trabalho, sobretudo no que diz respeito ao custo da mão de obra, no sentido de que, quanto mais rígido for o mercado de trabalho, maior será a dificuldade na geração de emprego. A segunda categoria refere-se às políticas ativas no mercado de trabalho destinadas a melhorar o funcionamento desse mercado para beneficiar os desempregados, reduzindo o desemprego de grupos espe- 
cíficos e de longo prazo, como também às políticas de treinamento e iniciativas que levem à criação direta de outros empregos (Ramos; Reis, 1997). Para auxiliar na execução dessas políticas ativas, é importante conhecer as características individuais que possam influenciar as decisóes dos indivíduos com relação à oferta de trabalho.

O presente trabalho tem como objetivo analisar os fatores microeconômicos que influenciam a situação de estar ocupado (PO), desempregado (PD) e fora do mercado de trabalho (PNEA). Serâo utilizados os microdados da Pesquisa Nacional de Amostra de Domicílios (PNAD) para os anos de 1995 e 2005, a fim de verificar se ocorreu algum tipo de mudança estrutural quanto a gênero, idade, escolaridade e condição na família.

$\mathrm{Na}$ primeira parte do artigo, serão analisados os fluxos de pessoas no mercado de trabalho na Região Sul do Brasil. $\mathrm{Na}$ sequência, apresenta-se o material teórico da search theory. $\mathrm{Na}$ terceira parte, tem-se o modelo econométrico e, finalmente, as consideraçôes finais.

\section{2_Referencial teórico}

A análise da situação das pessoas, com respeito a participar ou não da força de trabalho, deve incluir as forças que influenciam na oferta de trabalho, as quais, na maioria das vezes, estão associadas a aspectos de longo prazo, em razão do nascimento de novas empresas, da introdução de novas tecnologias e produtos, entre outros fatores.

O modelo mais conhecido relaciona-se à forma como o indivíduo aloca seu tempo entre horas de lazer e horas de trabalho. Com base nesse modelo, é determinada a curva de oferta de trabalho que relaciona salário e horas de trabalho. Tal relação pode ser positiva ou negativa, dependendo da magnitude do efeito substituição e do efeito renda.

É possível ampliar esse modelo ao considerar que a decisão de participar ou não do mercado de trabalho passa a ser uma decisão familiar, processo esse que se defronta, então, com três opçôes: trabalho no mercado, trabalho doméstico e lazer.

Além disso, é também viável analisar a oferta de trabalho dentro do aspecto do ciclo de vida, em que o salário e as horas de trabalhos variam ao longo desse ciclo. No início da vida adulta, mais horas são despendidas na educação e menos horas no trabalho. Espera-se que o tempo em trabalho remunerado tenha relação de concavidade para baixo com a idade. A perspectiva do ciclo de vida também é útil para se compreender 
a decisão dos trabalhadores de se aposen$\operatorname{tar}$ (Ehrenberg; Smith, 2000). As estimativas das elasticidades de oferta de trabalho encontradas são bastante amplas, tendo como consenso que tais estimativas dependem da taxa de participação do grupo analisado. Outro consenso diz respeito à elasticidade de oferta de trabalho para mulher casada e para o homem casado, sendo que tal elasticidade é positiva e maior para o primeiro grupo em relação ao segundo (Cahuc; Zylberberg, 2004).

A teoria neoclássica da oferta de trabalho não considera o tempo e o custo na procura por trabalho. O consumo de "lazer" - mesmo quando esse termo é estendido para atividade doméstica permanece considerando somente a alternativa entre o trabalho remunerado e o tempo gasto em lazer, cuja descrição diz respeito à categoria de náo participante no mercado de trabalho. Nessa perspectiva, não há lugar para as pessoas desempregadas, já que sua principal atividade seria a procura por trabalho. Tal descrição no mercado de trabalho implicitamente assume a estrutura de informação perfeita.

Essa hipótese é bastante simplista, e, ao relaxá-la e considerar a existência de informação imperfeita, estamos diante do modelo conhecido como job search theory. No mercado de trabalho, a imperfeição diz respeito às informaçóes disponíveis em relação aos diferentes níveis de salário. O indivíduo que está procurando trabalho tem como objetivo encontrar um trabalho que possibilite o salário mais elevado possível. O período da duração da procura por trabalho depende da sua preferência e da característica do ambiente do tomador de decisão. Essa teoria não é conflitante com a teoria da oferta de trabalho, pois, além de explicitar a existência da informação imperfeita, adiciona a categoria do "desempregado" às categorias já presentes de "empregado" e "não participante no mercado de trabalho". No modelo conhecido como job search model, a estratégia ótima do indivíduo que está procurando trabalho consiste simplesmente em escolher um salário de reserva que represente a menor remuneração que estaria disposta a aceitar (Cahuc; Zylberberg, 2004).

Fernandes e Picchetti (1999) analisaram a estrutura de desemprego e inatividade no Brasil utilizando os dados da PNAD de 1995 mediante um modelo logit multinomial. Os autores verificaram que a probabilidade de desemprego atinge seu máximo para indivíduos com cerca de nove anos de estudo e a probabilidade de inatividade é mais ele- 
vada para os indivíduos mais velhos e para os mais jovens. A menor probabilidade de inatividade foi verificada para indivíduos com 40 anos de idade. A probabilidade de desemprego é inicialmente crescente com a idade, e a tendência se inverte próximo aos 30 anos. Verificouse que as probabilidades de desemprego e da inatividade são mais elevadas para as mulheres.

Bukowshi e Lewandowski (2005) analisaram os fluxos de desemprego entre 1997-2004, na Polônia, quando ocorreram dois choques que afetaram a economia e seu mercado de trabalho. O foco principal diz respeito ao lado da oferta, ao identificar os fatores que influenciam a probabilidade de transição de desemprego, do emprego e inatividade, incluindo características pessoais e benefícios recebidos pelos desempregados, utilizando o modelo logit multinomial. Os autores verificaram que a transição para o emprego aumenta com o nível educacional e, ao analisar a idade, verificaram que os indivíduos entre 15 e 24 anos apresentam maior chance (em torno de $20 \%$ ) de estarem inativos em comparação com os indivíduos de 25-34 anos.

Voicu (2002) utilizou microdados para analisar o efeito do processo de reestruturação no mercado de trabalho na
România, para os anos de 1993, 1994 e 1995. O uso do modelo probit multivariado indicou significativo processo de realocação, em que se observou declínio do setor industrial, bem como aumento dos setores de serviços e comércio e também da agricultura. $\mathrm{O}$ interesse do autor era analisar a função do setor agrícola, uma vez que a qualidade de emprego nesse setor é menor. Quanto aos residentes rurais, mulheres e indivíduos com baixo nível de educação apresentaram maior probabilidade de trabalhar na agricultura. $\mathrm{O}$ setor agrícola tornou-se um destino para os indivíduos que estavam previamente desempregados. Esse processo ocorreu na România em razão das questóes institucionais relacionadas à reforma agrária. $\mathrm{O}$ trabalho no setor agrícola é transitório, já que há alta probabilidade de retornar ao trabalho no setor não agrícola. Trabalhadores com treinamento específico utilizam tanto a agricultura como a situação de desemprego como destino para sua transição para o setor não agrícola.

Dias e Mata (1997) estudaram o mercado de trabalho português, para o ano de 1994, no que diz respeito ao processo de transição utilizando microdados. Usaram um modelo logit em que a variável dependente apresenta a seguinte situação: a) trabalhador por conta pró- 
pria, b) empregado, c) desempregado e d) inativo. Os autores concluíram que a probabilidade de um homem e de uma mulher com características iguais à média da amostra estarem inativos é maior para a mulher (66\%) do que para o homem (33\%). Da mesma forma, a probabilidade de estar trabalhando por conta própria é maior para o homem (23\%) do que para a mulher (11\%). O efeito da educação indicou que, ao completarem o ensino superior, aumenta a probabilidade de estar empregado ou de estar desempregado à procura do primeiro emprego. Este último caso diz respeito às pessoas com alta escolaridade, mas sem experiência no mercado de trabalho.

Curi e Menezes-Filho (2006) analisaram o comportamento do mercado de trabalho brasileiro, no período entre 1984 a 2001, valendo-se dos dados longitudinais da pesquisa mensal de emprego (PME) utilizando um modelo logit multinomial, em que a variável dependente pode apresentar cinco possibilidades: 1) trabalhador no setor formal; 2) trabalhador no setor informal; 3) trabalhador por conta própria, 4) desempregado, e 5) fora do mercado de trabalho (saiu da PEA). As variáveis independentes foram: escolaridade, região metropolitana, gênero, idade, tempo. Todos os coeficientes foram significativos no mo- delo estimado. Os autores verificaram um aumento da transiçấo da formalidade para a informalidade ao longo do tempo, após o controle das características observáveis dos indivíduos. Esse aumento ocorreu principalmente a partir de 1990, por causa da liberalização econômica e das mudanças na legislação do trabalho, ocorridas na Constituição de 1988. O estudo dos efeitos marginais das variáveis explicativas sobre a formalidade indicou que o aumento da transição para fora da formalidade foi comum a todas as características (homem, mulher, com mais experiência e menos experiência, entre os mais e menos educados).

Corsini e Guerrazzi (2007) analisaram o mercado de trabalho italiano, que passou por grandes transformaçóes nos últimos dez anos, tendo como base as reformas institucionais que aumentaram a flexibilidade no mercado de trabalho. A avaliação desse processo levou a diferentes conclusões. Por um lado, o trabalho flexível pode se visto como um artifício para diminuir o custo de contratação e resolver o problema de seleção adversa por parte do empregador, durante o processo de contratação de novos trabalhadores. Desse ponto de vista, o emprego temporário pode ser considerado como uma etapa para a obtenção do emprego permanente. Por outro lado, 
o trabalho flexível pode ser um artifício para reduzir os custos do trabalho e gerar postos de trabalho precários.

Para analisar esse fenômeno, foi estimada a probabilidade de transição de trabalho temporário para trabalho permanente, treinamento, desemprego, com base em um modelo multinomial nested logit (MNLMs). Concluiu-se que os trabalhadores jovens apresentavam menor probabilidade de conseguir um trabalho permanente, visto que a possível falta de experiência pode ser um obstáculo para conseguir o trabalho permanente. A probabilidade da obtenção de um trabalho permanente cresce com a idade e atinge um máximo com 35 anos, depois começa a diminuir. Há uma probabilidade maior de conseguir um trabalho permanente para o homem em comparação com a mulher. A educação tem impacto importante sobre a probabilidade de transição. Em geral, maiores níveis de educação oferecem maior chance de conseguir trabalho.

Ollikainen (2006) analisou a diferença entre gênero no mercado de trabalho na Finlândia, em 1996, com base em um modelo multinomial logit, em que estimou a probabilidade de transição do desemprego para o emprego e para fora do mercado de trabalho. Verificou que as pessoas que transitam do desempre- go para o emprego têm características diferentes daquelas que transitam do desemprego para fora do mercado de trabalho. Os resultados obtidos indicaram que os jovens têm algumas vantagens para conseguir um emprego, e que homens jovens têm maior probabilidade de conseguir um emprego do que as mulheres. Ademais, homens com idade entre 25 e 39 anos têm $7 \%$ a mais de probabilidade de conseguir um emprego; homens casados têm maior probabilidade de estarem empregados; mulheres casadas e solteiras apresentaram a mesma probabilidade de estarem empregadas; e, mulheres mais escolarizadas têm maior probabilidade de encontrar trabalho do que as mulheres menos escolarizadas. Mulheres com ensino fundamental apresentaram menor probabilidade de encontrar emprego do que os homens; já as mulheres com maior escolaridade apresentaram maior probabilidade de encontrar emprego do que os homens.

A educação, para os homens, tem o papel de prevenir o seu deslocamento. Os homens com maior educação possuem menor probabilidade de sair do mercado de trabalho. Verificou-se, ainda, que homens com histórico de desemprego são mais penalizados do que as mulheres na mesma posição na busca de emprego. Os resultados apontaram que 
a educação tem a função de promover maior igualdade no mercado de trabalho, uma vez que há correlação altamente positiva entre educação e probabilidade de conseguir emprego, tanto para os homens como para as mulheres. No entanto, para as mulheres o benefício da educação é particularmente maior do que para os homens.

A análise dos estudos citados aqui permite algumas conclusóes, a saber: a importância do papel da educação na transição no mercado de trabalho, bem como da idade, do gênero e mudanças institucionais.

\section{3_Metodologia}

A base de dados utilizada foram os microdados da PNAD para os anos de 1995 e 2005. Quanto às variáveis, foi considerada variável dependente a situação das pessoas no mercado de trabalho, englobando três possibilidades: 1) Pessoas Ocupadas (PO) - período de referência de 365 dias; 2) Pessoas Desocupadas (PD) - período de referência de 365 dias; e 3) Foram consideradas inativas as pessoas que se encontravam fora do mercado de trabalho - período de referência de 365 dias (PNEA - população não economicamente ativa). A idade das pessoas analisadas estava no intervalo entre $16 \mathrm{e}$
70 anos. $\mathrm{O}$ modelo econométrico analisa o Brasil, sendo adicionados dummies regionais para Curitiba (PR), Florianópolis (SC) e Porto Alegre (RS). As variáveis independentes foram as seguintes:

- Anosestudo: anos de estudo, para medir o nível de escolaridade

- Anoestudo2: anos de estudo ao quadrado

- Homem: dummy de gênero, igual a 1 se for homem, igual a zero(0) se for mulher

- Renda: renda familiar per capita

- Idade: idade

- Idade2: idade ao quadrado

- RM21: dummy da Região Metropolitana de Curitiba (PR)

- RM22: dummy da Região Metropolitana de Florianópolis (SC)

- RM23: dummy da Regiâo Metropolitana de Porto Alegre (RS)

- TFAM1: dummy de casal sem filhos

- TFAM2: dummy de casal com todos os filhos menores de 14 anos

- TFAM3: dummy de casal com todos os filhos maiores de 14 anos

- TFAM6: Mãe com todos os filhos menores de 14 anos

- TFAM7: Mãe com todos os filhos de 14 anos ou mais

- Filho: dummy condição na família: um se for filho, zero para outras condiçóes 


\section{4_Modelo econométrico}

Ao estimar esse modelo por OLS (modelo de probabilidade linear), haverá dois problemas: impóe uma relação linear inexistente, e a forma funcional não é limitada, o que viola a lei de probabilidade, já que a probabilidade não pode ser maior que um. Para resolver esse problema, é preciso utilizar um estimador de mínimo quadrado não linear ou utilizar máxima verossimilhança. Ao empregar esses estimadores, a curva terá a forma de um $S$ e estará limitada entre zero e um, respeitando-se, assim, a lei da probabilidade. Especificamente neste artigo será utilizado um modelo logit multinomial, em que o erro aleatório tem distribuição logística. A seguir, apresenta-se o modelo logit multinomial.

Seja y uma variável aleatória assumindo os valores $\{0,1, \ldots, \mathrm{J}\}$ para $\mathrm{J}$ inteiro positivo, e seja $\mathbf{x}$ um conjunto variáveis condicionais. Neste artigo, y denota as possíveis posiçóes no mercado de trabalho (ocupado, desempregado e inativo) e $\mathbf{x}$ contém informaçóes a respeito de idade, escolaridade, gênero, etc. Como é comum, $\left(\mathrm{x}_{\mathrm{i}}, \mathrm{y}_{\mathrm{i}}\right)$ é uma amostra aleatória da população.

Estamos interessados em verificar como a mudança ceteris paribus nos elementos de $\mathbf{x}$ afeta a probabilidade de estar ocupado, desempregado e inati- vo, $P(y=j / \mathbf{x}), j=0,1,2, \ldots$, J. Seja $\mathbf{x}$ um vetor $1 \mathrm{x} \mathrm{K}$ com o primeiro elemento unitário. O Modelo Multinomial Logit (MNL), segundo Wooldridge (2002), tem a probabilidade:

$$
\begin{aligned}
P(y= & j / x)=\exp \left(x \beta_{j}\right) / \\
& /\left[1+\sum_{h=1}^{J} \exp \left(x \beta_{h}\right)\right], \mathrm{j}=1, \ldots, \mathrm{J}
\end{aligned}
$$

onde $\beta_{j}$ é $\mathrm{K} \times 1, \mathrm{j}=1, \ldots, \mathrm{J}$.

Como a soma da probabilidade deve ser igual a 1, então se tem:

$$
\begin{aligned}
P(y= & 0 / x)= \\
& =1 /\left[1+\sum_{h=1}^{J} \exp \left(x \beta_{h}\right)\right]
\end{aligned}
$$

Quando $\mathrm{J}=1, \beta_{1}$ é o vetor $\mathrm{K} \mathrm{x}$ 1 de parâmetros desconhecidos e tem-se, então, um modelo logit binário.

Os coeficientes desse modelo são mais difíceis de ser interpretados em comparação com modelos lineares; por isso, para facilitar essas interpretaçóes, são estimados os efeitos marginais, que são a derivada parcial das probabilidades de transição, calculados da seguinte forma (Ollikainen, 2006): 
$\frac{\partial P_{i j}}{\partial x_{i}}=P_{i j}\left[\beta_{j}-\sum_{K=1}^{J} P_{i k} \beta_{k}\right]$

Tendo completamente especificado a densidade de y dado x, a melhor estimação do modelo logit multinomial é obtida pela função de máxima verossimilhança. Para cada i, a função log-verossimilhança condicional pode ser escrito como:

$l_{i}(\beta)=\sum_{j=0}^{J} 1\left[y_{i}=j\right] \log \left[p_{j}\left(x_{i}, \beta\right)\right]$

onde a função indicador seleciona a apropriada probabilidade para cada observação i. Como é usual, a estimativa $\beta$ maximiza $\sum_{i=1}^{N} l_{i}(\beta)$.

O modelo logit multinomial deve apresentar uma característica necessária e suficiente conhecida como independent from irrelevant alternatives
(IIA) - independência da alternativa irrelevante - que informa que a razão da probabilidade da escolha de duas alternativas quaisquer é independente da disponibilidade de uma terceira alternativa. Essa condiçãao foi testada pelo método desenvolvido por Hausman e MacFadden (1984).

Na próxima seção, serão analisados os resultados obtidos. Será apresentada uma estatística descritiva entre taxa de inatividade, taxa de desemprego, por gênero, por nível de escolaridade, por idade; na sequência, tem-se o resultado do modelo logit multinomial.

\section{5_Resultados}

Conforme apresentado anteriormente, as pessoas podem estar em três possíveis situaçóes: ocupadas, desempregadas e inativas. Na Tabela 1, a seguir,

Tabela 1 _ Taкa de inatividade no Brasil e na Região Sul em 1995 e 2005 (\%)

\begin{tabular}{|c|c|c|c|c|c|c|}
\hline & \multicolumn{2}{|c|}{ Homem } & \multicolumn{2}{|c|}{ Mulher } & \multicolumn{2}{|c|}{ Total } \\
\hline & 1995 & 2005 & 1995 & 2005 & 1995 & 2005 \\
\hline Paraná & 6,7 & 9,8 & 32,9 & 28,5 & 20,1 & 19,5 \\
\hline Santa Catarina & 6,7 & 10,6 & 30,7 & 27,7 & 18,7 & 19,4 \\
\hline Rio Grande do Sul & 9,1 & 10,6 & 30,1 & 26,9 & 20,1 & 19,0 \\
\hline Brasil & 9,8 & 11,5 & 37,2 & 31,4 & 24,0 & 21,8 \\
\hline
\end{tabular}

Fonte: Microdados PNAD. 
tem-se a taxa de inatividade por gênero, que diz respeito à percentagem de pessoas que estão fora do mercado de trabalho. Observa-se que a taxa de inatividade, tanto para o homem como para a mulher, é menor na Região Sul, comparativamente com o Brasil. Além disso, essa taxa é menor para os homens do que para mulheres. O comportamento da taxa de inatividade variou entre os anos de 19952005, principalmente no que concerne às mulheres, com relação ao Brasil, indicando um fenômeno conhecido na literatura, que diz respeito ao aumento da participação da mulher no mercado de trabalho, aumento esse que foi mais significativo no Rio Grande do Sul. Nota-se um comportamento contrário com relação aos homens, pois se verifica aumento da taxa de inatividade nesse período.

A taxa de desemprego no Brasil e na Região Sul, entre 1995 e 2005, indi- cou aumento do desemprego no Brasil, tanto para os homens como para as mulheres. Esse aumento foi mais acentuado para as mulheres em termos absolutos, em que a taxa de desemprego passou de $6,1 \%$ para $10,2 \%$. Entre os fatores que contribuíram para isso está o aumento da participação da mulher no mercado de trabalho. Na Região Sul, o Estado de Santa Catarina apresentou menor taxa de desemprego. A taxa de desemprego para o homem foi menor do que para as mulheres para os três Estados da região, nos dois períodos analisados (Tabela 2).

A relação entre a taxa de inatividade e anos de estudo indica ser decrescente, isto é, à medida que aumentam os anos de estudo, diminuem os números de pessoas que estão foram do mercado de trabalho. Essa queda é mais acentuada na Região Sul, comparativamente com o Brasil (Tabela 3).

Tabela 2 _ Taxa de desemprego no Brasil e na Região Sul em 1995 e 2005 (\%)

\begin{tabular}{l|c|c|c|c|c|c} 
& \multicolumn{2}{c}{ Homem } & \multicolumn{2}{c|}{ Mulher } & \multicolumn{2}{c}{ Total } \\
\cline { 2 - 7 } & $\mathbf{1 9 9 5}$ & $\mathbf{2 0 0 5}$ & $\mathbf{1 9 9 5}$ & $\mathbf{2 0 0 5}$ & $\mathbf{1 9 9 5}$ & $\mathbf{2 0 0 5}$ \\
\hline Paraná & 1,2 & 3,0 & 4,6 & 5,8 & 2,6 & 4,3 \\
\hline Santa Catarina & 1,0 & 1,5 & 2,9 & 5,0 & 1,8 & 3,1 \\
\hline Rio Grande do Sul & 1,7 & 2,6 & 4,4 & 6,7 & 2,9 & 4,5 \\
\hline Brasil & 2,4 & 4,3 & 6,1 & 10,2 & 4,0 & 7,0
\end{tabular}


Tabela 3 _ Taxa de inatividade e anos de estudo no Brasil e na Região Sul em 1995 e 2005

\begin{tabular}{|c|c|c|c|c|c|c|c|c|}
\hline \multirow{2}{*}{$\begin{array}{l}\text { Anos de } \\
\text { Estudo }\end{array}$} & \multicolumn{2}{|c|}{ Paraná } & \multicolumn{2}{|c|}{ Santa Catarina } & \multicolumn{2}{|c|}{ Rio Grande do Sul } & \multicolumn{2}{|c|}{ Brasil } \\
\hline & 1995 & 2005 & 1995 & 2005 & 1995 & 2005 & 1995 & 2005 \\
\hline Menos 1 & 36,2 & 39,6 & 29,5 & 43,2 & 34,5 & 39,6 & 31,1 & 33,6 \\
\hline 1 a 3 & 22,3 & 31,1 & 21,6 & 31,6 & 24,1 & 27,0 & 25,3 & 26,0 \\
\hline 4 a 7 & 17,2 & 21,2 & 18,2 & 22,6 & 18,7 & 21,4 & 24,6 & 24,4 \\
\hline 8 a 10 & 21,2 & 18,9 & 20,1 & 18,9 & 23,6 & 20,6 & 25,8 & 24,4 \\
\hline 11 a 14 & 16,4 & 12,5 & 15,6 & 12,7 & 15,9 & 13,0 & 17,5 & 14,2 \\
\hline 15 ou mais & 8,6 & 10,0 & 7,4 & 10,7 & 8,3 & 10,2 & 10,0 & 10,6 \\
\hline Total & 20,1 & 19,5 & 18,7 & 19,4 & 20,1 & 19,0 & 24,0 & 21,8 \\
\hline
\end{tabular}

Fonte: Microdados PNAD.

A relação entre a taxa de desemprego e os anos de estudo pode ser representada como uma parábola com um ponto de máximo. Isto é, à medida que se aumentam os anos de estudos, há elevação da taxa de desemprego, que atinge um máximo e depois começa a diminuir. A faixa de 8 a 10 anos de estudos mostra maior taxa de desemprego (Tabela 4). É conhecido na literatura, conforme apontam Camargo, Neri, e Reis (2000), um aumento na escolaridade das pessoas entre $1995 \mathrm{e}$ 2005. Dessa forma, a taxa de desemprego está relacionada com o fluxo de pessoas, isto é, número de pessoas por faixa de estudos e o tamanho da força de trabalho.

Tabela 4 Taka de desemprego e anos de estudos no Brasil e na Região Sul em 1995 e 2005

\begin{tabular}{|c|c|c|c|c|c|c|c|c|}
\hline \multirow{2}{*}{$\begin{array}{l}\text { Anos de } \\
\text { Estudo }\end{array}$} & \multicolumn{2}{|c|}{ Paraná } & \multicolumn{2}{|c|}{ Santa Catarina } & \multicolumn{2}{|c|}{ Rio Grande do Sul } & \multicolumn{2}{|c|}{ Brasil } \\
\hline & 1995 & 2005 & 1995 & 2005 & 1995 & 2005 & 1995 & 2005 \\
\hline Menos 1 & 1,7 & 1,4 & 0,4 & 4,1 & 1,3 & 2,4 & 1,8 & 3,3 \\
\hline 1 a 3 & 1,3 & 3,8 & 0,9 & 1,1 & 2,8 & 3,4 & 2,8 & 3,9 \\
\hline 4 a 7 & 2,5 & 3,6 & 1,8 & 1,7 & 1,9 & 3,1 & 3,8 & 5,7 \\
\hline 8 a 10 & 5,0 & 8,1 & 3,3 & 4,6 & 5,2 & 6,5 & 6,9 & 11,1 \\
\hline 11 a 14 & 2,7 & 3,9 & 2,5 & 3,9 & 3,4 & 5,3 & 4,6 & 8,3 \\
\hline 15 ou mais & 1,3 & 1,6 & 0,0 & 2,0 & 2,0 & 2,3 & 1,9 & 3,0 \\
\hline Total & 2,6 & 4,3 & 1,8 & 3,1 & 2,9 & 4,5 & 4,0 & 7,0 \\
\hline
\end{tabular}

Fonte: Microdados PNAD. 
Tabela 5 _ Taxas de inatividade por idade no Brasil e na Região Sul em 1995 e 2005

\begin{tabular}{c|c|c|c|c|c|c|c|c}
\hline \multirow{2}{*}{$\begin{array}{c}\text { Faixa Etária } \\
\text { (anos) }\end{array}$} & \multicolumn{2}{|c|}{ Paraná } & \multicolumn{2}{c|}{ Santa Catarina } & \multicolumn{2}{c|}{ Rio Grande do Sul } & \multicolumn{2}{c}{ Brasil } \\
\cline { 2 - 9 } & $\mathbf{1 9 9 5}$ & $\mathbf{2 0 0 5}$ & $\mathbf{1 9 9 5}$ & $\mathbf{2 0 0 5}$ & $\mathbf{1 9 9 5}$ & $\mathbf{2 0 0 5}$ & $\mathbf{1 9 9 5}$ & $\mathbf{2 0 0 5}$ \\
\hline $\mathbf{1 6}$ a 20 & 21,7 & 25,0 & 19,7 & 23,2 & 27,4 & 28,9 & 31,2 & 32,5 \\
\hline 21 a 30 & 14,5 & 10,8 & 12,8 & 8,7 & 13,2 & 9,6 & 17,1 & 12,9 \\
\hline 31 a 45 & 14,3 & 12,0 & 13,5 & 11,4 & 11,9 & 10,1 & 15,9 & 13,1 \\
\hline 46 a 60 & 25,9 & 24,9 & 25,3 & 27,9 & 24,7 & 22,4 & 29,4 & 26,3 \\
\hline 61 a 70 & 52,5 & 55,1 & 50,0 & 58,6 & 53,2 & 52,8 & 57,7 & 57,7 \\
\hline Total & 20,1 & 19,5 & 18,7 & 19,4 & 20,1 & 19,6 & 24,0 & 21,8 \\
\hline
\end{tabular}

Fonte: Microdados PNAD.

A relação entre taxa de inatividade e idade apresenta-se em forma de parábola com um ponto de mínimo. Tal resultado é esperado, já que está em conformidade com a expectativa de ciclo de vida das pessoas: quando jovens, estâo estudando e fora do mercado de trabalho, e, à medida que aumenta a idade, cresce a sua participação no mercado de trabalho, o que coincide com a taxa de inatividade mínima, cuja faixa etária é entre 31 e 45 anos (Tabela 5).

A relação entre a taxa de desemprego e a idade apresenta-se negativa (Tabela 6). É esperado que a taxa de desemprego seja mais intensa para os jovens e para as pessoas mais velhas. $\mathrm{Na}$ faixa etária entre 16 e 20 anos, o aumento da taxa de desemprego entre 1995 e 2005 foi mais acentuado no Paraná.

Tabela 6 _ Taxas de desemprego por idade no Brasil e na Região Sul em 1995 e 2005

\begin{tabular}{|c|c|c|c|c|c|c|c|c|}
\hline \multirow{2}{*}{$\begin{array}{c}\text { Faixa Etária } \\
\text { (anos) }\end{array}$} & \multicolumn{2}{|c|}{ Paraná } & \multicolumn{2}{|c|}{ Santa Catarina } & \multicolumn{2}{|c|}{ Rio Grande do Sul } & \multicolumn{2}{|c|}{ Brasil } \\
\hline & 1995 & 2005 & 1995 & 2005 & 1995 & 2005 & 1995 & 2005 \\
\hline 16 a 20 & 6,1 & 13,5 & 4,6 & 9,3 & 8,4 & 15,2 & 10,1 & 18,8 \\
\hline 21 a 30 & 2,7 & 4,8 & 1,8 & 3,9 & 3,2 & 4,8 & 4,6 & 8,4 \\
\hline 31 a 45 & 1,9 & 2,4 & 1,5 & 1,8 & 2,1 & 2,8 & 2,4 & 4,3 \\
\hline 46 a 60 & 1,4 & 2,2 & 0,7 & 1,0 & 1,4 & 2,4 & 1,5 & 3,1 \\
\hline 61 a 70 & 1,0 & 2,1 & 0,0 & 1,0 & 1,2 & 2,1 & 1,4 & 2,4 \\
\hline Total & 2,6 & 4,3 & 1,8 & 3,1 & 2,9 & 4,5 & 4,0 & 7,0 \\
\hline
\end{tabular}

Fonte: Microdados PNAD. 
O teste estatístico a respeito do IIA (independent from irrelevant alternatives) não foi rejeitado, o que indica que o modelo econométrico é apropriado (no Anexo). Com base nesse modelo, é possível determinar a previsão da probabilidade de as pessoas estarem ocupadas à medida que variam os anos de estudos. O Gráfico 1 apresenta uma relação positiva entre a probabilidade de estar ocupado e os anos de estudo, mostrando pequena diferença entre os anos de $1995 \mathrm{e}$ 2005, principalmente para os anos iniciais de estudo.

Com base no modelo econométrico sugerido, é possível encontrar uma relação positiva decrescente, apresentando um ponto de máximo entre pessoas desempregadas e anos de estudos. A probabilidade de estar desempregado foi mais intensa em 2005 (Gráfico 2), notadamente na faixa de 10 a 11 anos de estudos. Isso ocorreu porque houve aumento da escolaridade entre 1995 e 2005, bem como o mercado passou a exigir mão de obra mais qualificada.

A relação entre probabilidade de estar inativo e anos de estudos indica ser negativa (Gráfico 3), isto é, à medida que aumentam os anos de estudos, diminui a probabilidade de estar inativo. Para os anos iniciais de estudo, a probabilidade de estar inativo é ligeiramente maior em 2005.

\section{Gráfico 1_Relação entre probabilidade de estar ocupado e anos de estudos - 1995 e 2005}

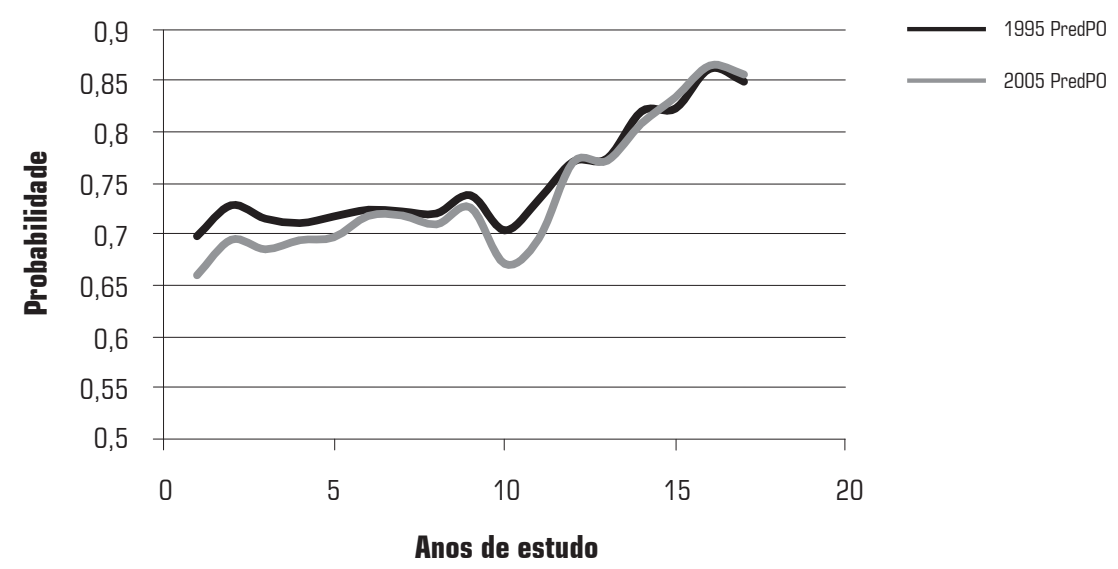

Fonte: Microdados PNAD. 
Gráfico 2_ Relação entre probabilidade de estar desempregado e anos de estudos - 1995 e 2005

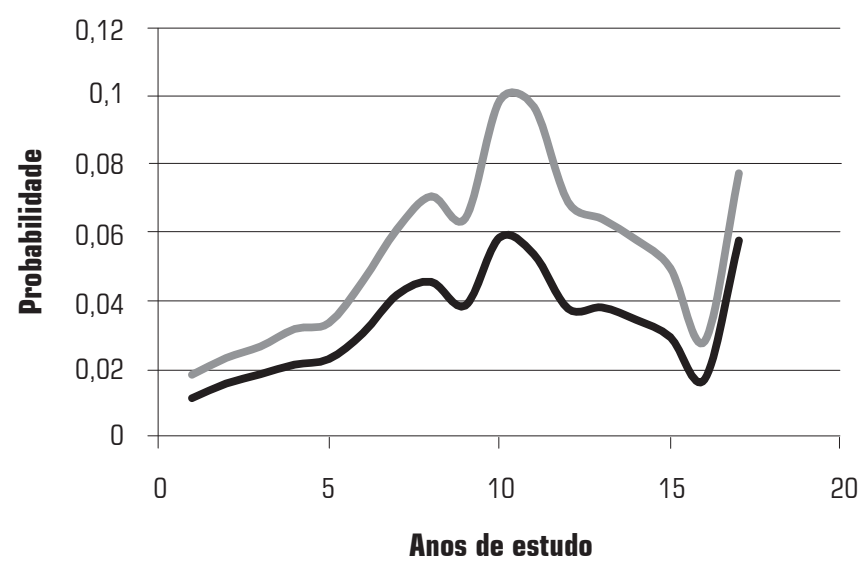

Fonte: Microdados PNAD.

Gráfico 3_Relação entre probabilidade de estar inativo e anos de estudos - 1995 e 2005

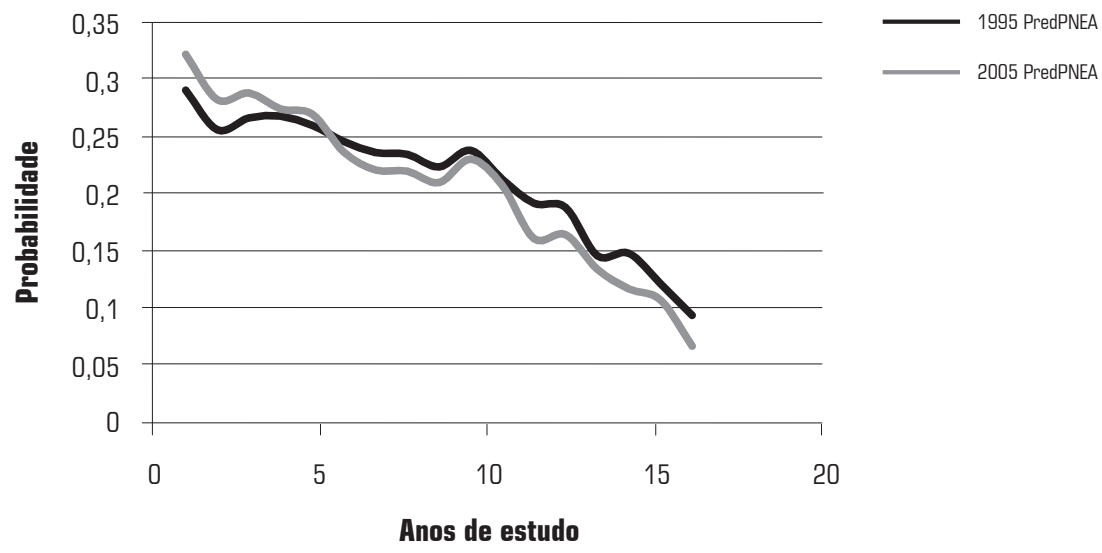

Fonte: Microdados PNAD. 
O comportamento da probabilidade de estar ocupado e idade apresenta relação positiva decrescente, atingindo um ponto de máximo por volta dos 40 anos, não ocorrendo diferença significativa entre os anos de 1995 e 2005 (Gráfico 4). O comportamento da relação de tais variáveis está de acordo com a teoria do ciclo de vida, na qual os jovens deveriam estar estudando e, desta forma, fora do mercado de trabalho. Esses jovens entrariam no mercado de trabalho mais tarde, com maior nível de qualificação. À medida que a idade avança, as pessoas tendem a sair no mercado de trabalho; nesse momento, defrontam-se com a decisão a respeito de se aposentarem, e a tendência atual é que tal decisão seja adiada, em função do aumento da expectativa de vida, entre outros fatores.

Schmitt e Ribeiro (2004) estudaram a participação feminina no mercado trabalho em Porto Alegre, para o ano de 1995, utilizando regressóes baseadas no modelo logit, cuja variável dependente do modelo era uma variável dummy que informava se a mulher participava ou não do mercado de trabalho. Os resultados obtidos pelos autores foram: ocorre um aumento da probabilidade de a mulher participar do mercado de trabalho, caso ela seja chefe de família, e que a idade é um fator importante na

\section{Gráfico 4_Relação entre probabilidade de estar ocupado e idade - 1995 e 2005}

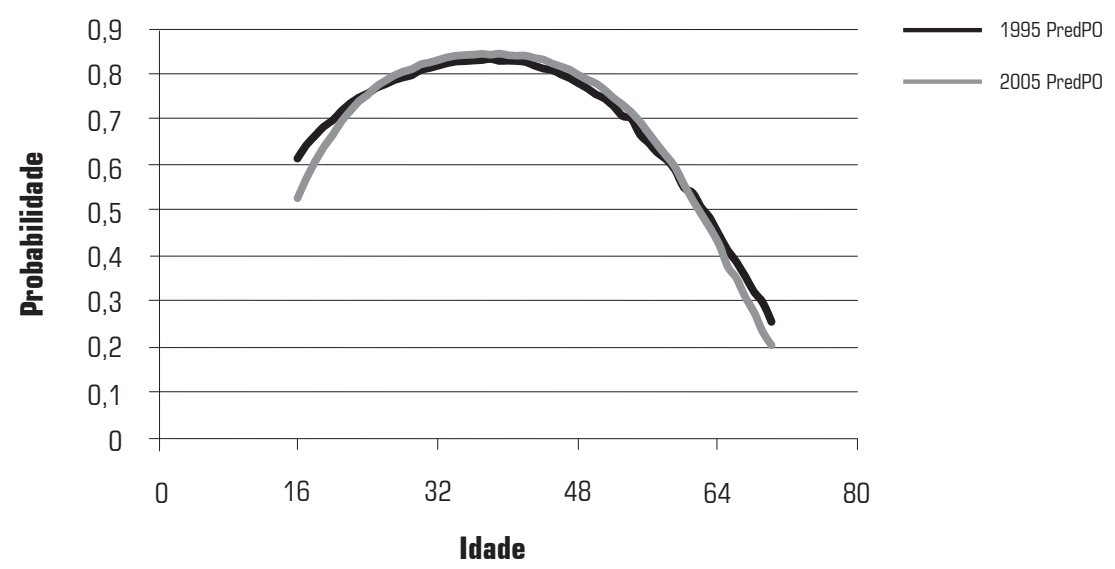

Fonte: Microdados PNAD. 
decisão da mulher de participar ou não no mercado de trabalho. A probabilidade de a mulher se inserir no mercado de trabalho (PEA) aumenta até os 23 anos; a partir dessa idade, a probabilidade começa a diminuir.

Ao se analisar a probabilidade de estar desempregado e a idade, verifica-se uma relação decrescente, com um ponto de máximo localizado aproximadamente aos 16 anos (Gráfico 5). Esse resultado está de acordo com a literatura, em que se verifica maior taxa de desemprego para os jovens entre 18 e 25 anos, conforme apontado por Pochmann (2000). A partir dos 30 anos, a probabilidade de estar desempregado continua decrescente com a idade, mas de maneira menos intensa. A probabilidade de estar desempregado foi mais intensa em 2005, comparativamente a 1995.

A relação entre a probabilidade de estar inativo e idade apresenta-se negativa e crescente com um ponto de mínimo por volta dos 40 anos (Gráfico 6). Assim, pode-se perceber aumento da probabilidade de estar inativo a partir dos 40 anos, resultado semelhante ao obtido por Fernandes e Picchetti (1999). Tal resultado está relacionado com a diminuição da probabilidade de a pessoa estar ocupado nessa faixa etária. Desse modo, a diminuição da probabilidade de a pessoa estar desempregado nessa faixa etária se deve ao fato de ela estar prestes a sair do mercado de trabalho.

\section{Gráfico 5_Relação entre probabilidade de estar desempregado e idade - 1995 e 2005}

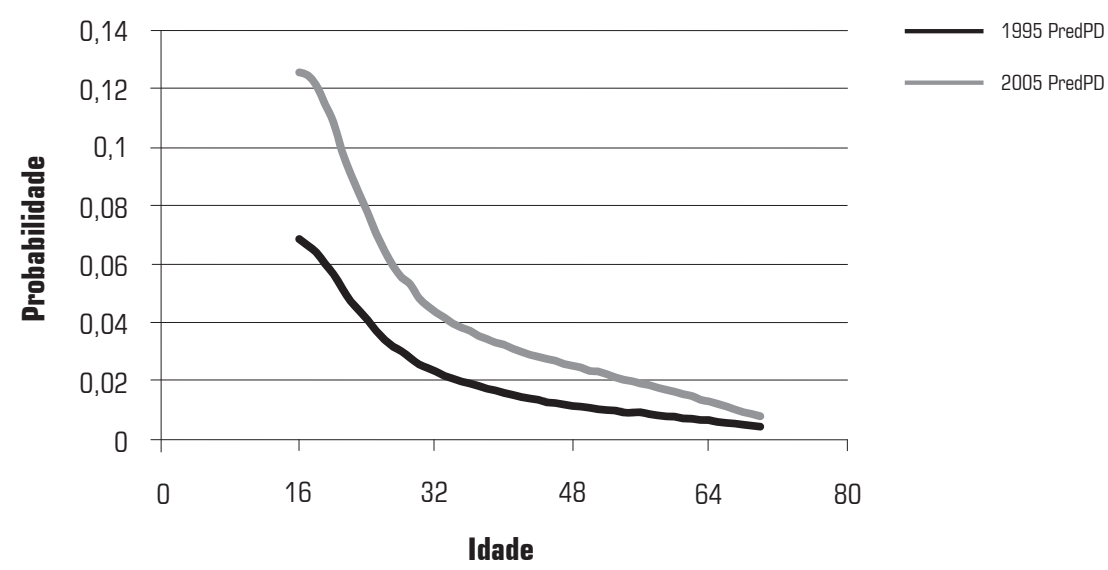

Fonte: Microdados PNAD. 


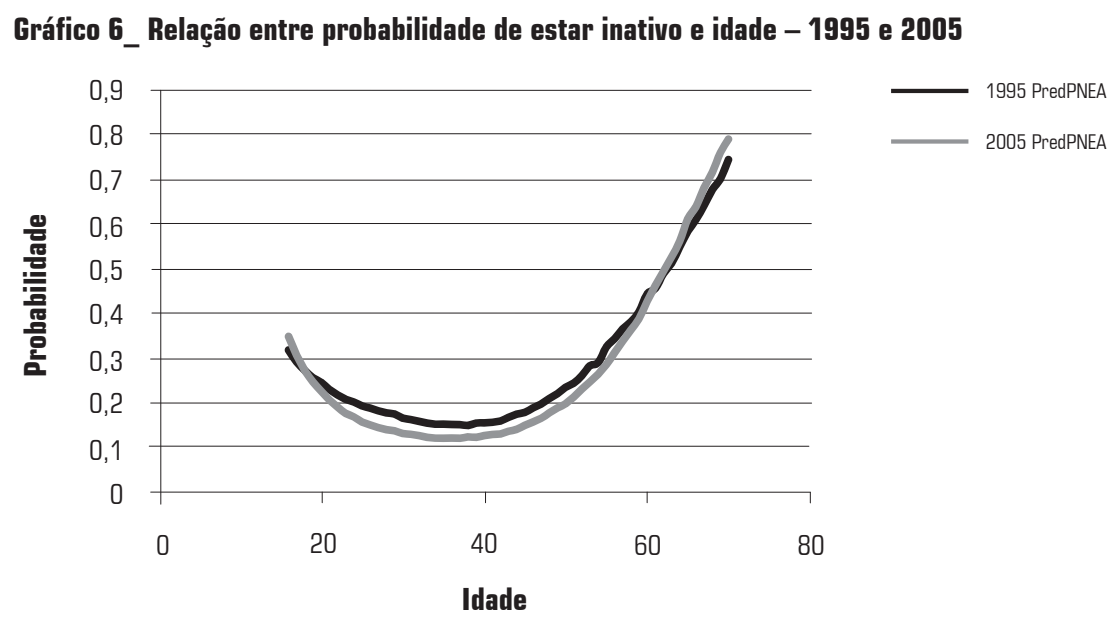

Fonte: Microdados PNAD.

A comparação da probabilidade bilidade de estar ocupado era maior em de estar ocupado na Regiāo Sul e no Bra- Santa Catarina, posição que passou a ser sil, em 1995 e 2005, apontou diminuição ocupada pelo Rio Grande do Sul, em para todas as regióes. Em 1995, a proba2005 (Gráfico 7).

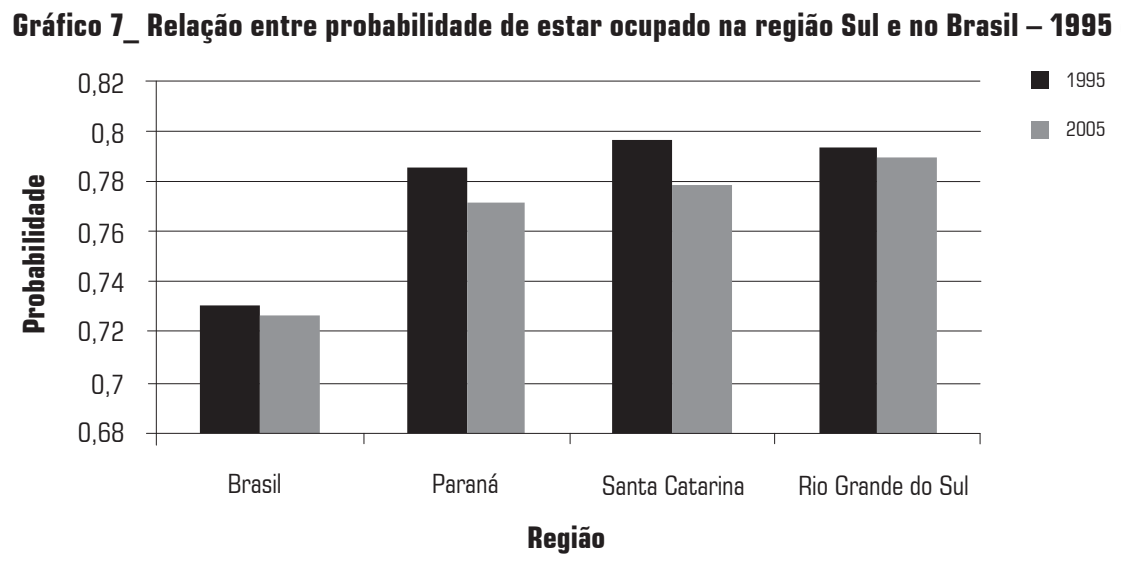

Fonte: Microdados PNAD. 
No que diz respeito à probabilidade de estar desempregado na Região Sul e no Brasil, em 1995 e 2005, verifica-se que ocorreu aumento nesse período, o qual foi mais intenso no Brasil do que na Regiāo Sul. A probabilidade de estar desempregado foi menor em Santa Catarina para os dois períodos analisados (Gráfico 8).

Já com relação à probabilidade de estar inativo em 1995 e 2005, não ocorreu grande variação na Regiāo Sul (Gráfico 9), o que está relacionado a dois fatores: o primeiro diz respeito à taxa de natalidade, à taxa de mortalidade e à taxa de migração da região, referindo-se às pessoas dentro e fora do mercado de trabalho. O segundo está associado à taxa de crescimento dos postos de trabalho da região e ao nível de renda da população. Tais fatores influenciam na entrada e na saída de pessoas no mercado de trabalho.

Ao se analisar a diferença de gênero, verifica-se que a probabilidade de estar ocupado era menor para a mulher do que para o homem, tanto em 1995 como em 2005, no Brasil e na Região Sul (Tabela 7). Nesse período, ocorreu, para o homem, diminuição da probabilidade de estar ocupado, e, para a mulher, essa probabilidade permaneceu aproximadamente estável.

A situação de desemprego, em 1995 e 2005, refletiu aumento da probabilidade de estar desempregado tanto para o homem como para a mulher, no Brasil e na Região Sul (Tabela 8).

\section{Gráfico 8_Relação entre probabilidade de estar desempregado} na regiáo Sul e no Brasil - 1995 e 2005

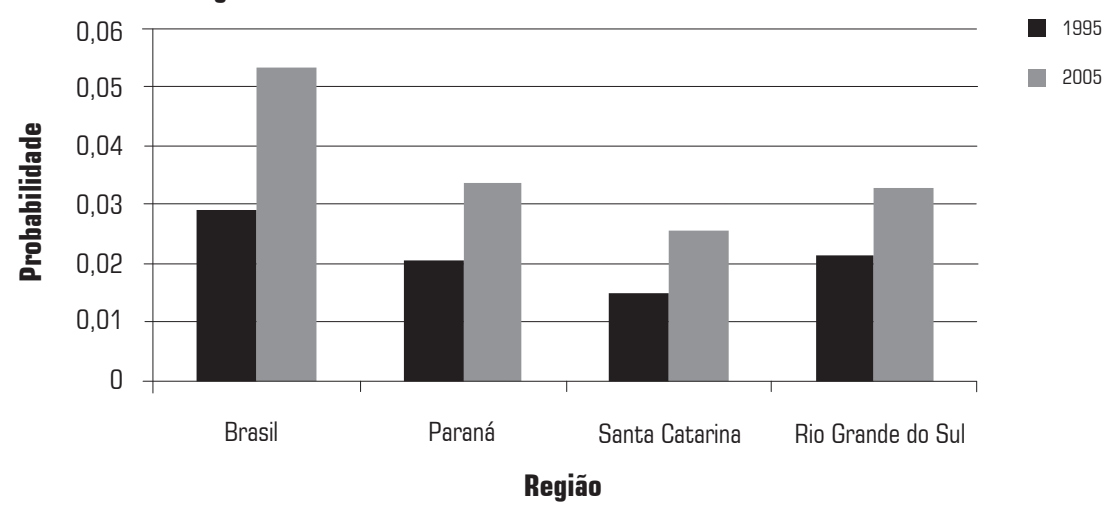

Fonte: Microdados PNAD. 
A relação entre inativo, gênero e região geográfica, em 1995 e 2005, indicou que a probabilidade de estar inativo é maior entre as mulheres, principalmente no Brasil. Tal probabilidade foi menor no Rio Grande do Sul (Tabela 9).
Gruber, Campos e Lima (2009) analisaram o mercado de trabalho urbano da Regiáo Sul do Brasil tomando por base o índice Saboia, para o período de 2000 e 2007, utilizando dados para 36 cidades médias da Região Sul, mais as três

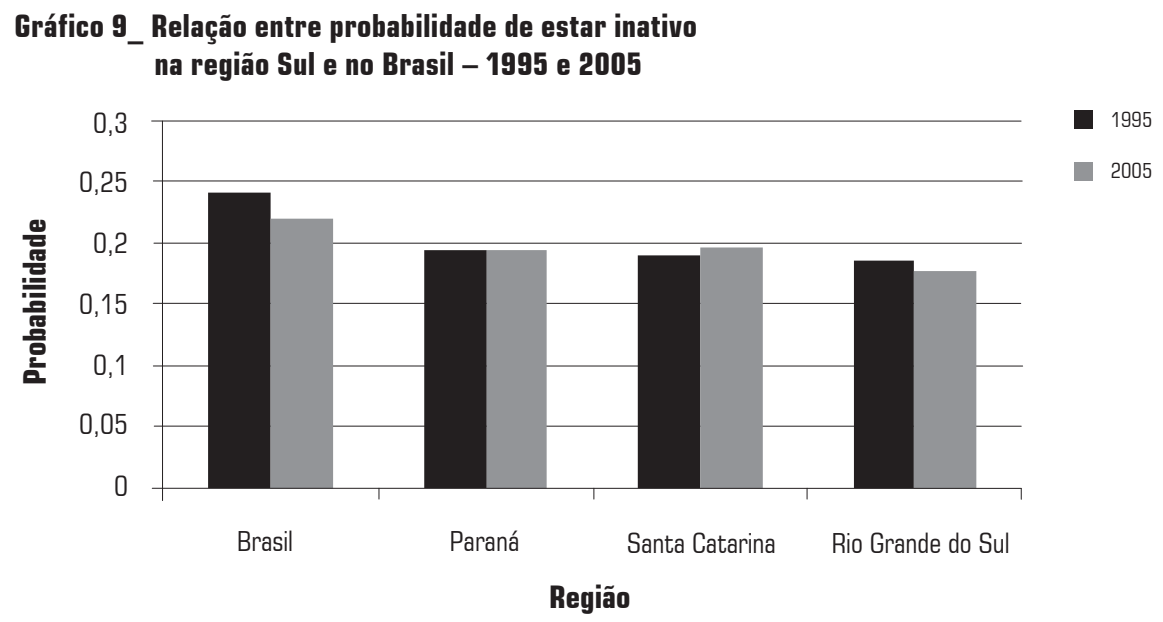

Fonte: Microdados PNAD.

Tabela 7 _ Probabilidade de estar ocupado por gênero no Brasil e na Região Sul - 1995 e 2005

\begin{tabular}{l|c|c|c|c}
\multirow{2}{*}{} & \multicolumn{2}{|c|}{$\mathbf{1 9 9 5}$} & \multicolumn{2}{c}{$\mathbf{2 0 0 5}$} \\
\cline { 2 - 5 } & Homem & Mulher & Homem & Mulher \\
\hline Brasil & 0,8444 & 0,5883 & 0,8474 & 0,6153 \\
\hline Paraná & 0,9138 & 0,6624 & 0,8802 & 0,6712 \\
\hline Santa Catarina & 0,9220 & 0,6708 & 0,8852 & 0,6778 \\
\hline Rio Grande do Sul & 0,9194 & 0,6780 & 0,8919 & 0,6942
\end{tabular}

Fonte: Microdados PNAD. 
Tabela 8 _ Probabilidade de estar desempregado por gênero no Brasil e na Região Sul - 1995 e 2005

\begin{tabular}{l|c|c|c|c}
\multirow{2}{*}{} & \multicolumn{2}{|c|}{$\mathbf{1 9 9 5}$} & \multicolumn{2}{c}{$\mathbf{2 0 0 5}$} \\
\cline { 2 - 5 } & Homem & Mulher & Homem & Mulher \\
\hline Brasil & 0,0204 & 0,0366 & 0,0371 & 0,0687 \\
\hline Saraná & 0,0144 & 0,0268 & 0,0225 & 0,0437 \\
\hline Rio Grande do Sul & 0,0103 & 0,0196 & 0,0172 & 0,0335 \\
\hline
\end{tabular}

Fonte: Microdados PNAD.

Tabela 9 _ Probabilidade de estar inativo por gênero no Brasil e na Região Sul - 1995 e 2005

\begin{tabular}{l|l|l|l|l} 
& \multicolumn{2}{|c}{$\mathbf{1 9 9 5}$} & \multicolumn{2}{c}{ 2005 } \\
\cline { 2 - 5 } & Homem & Mulher & Homem & Mulher \\
\hline Brasil & 0,0952 & 0,3751 & 0,1155 & 0,3160 \\
\hline Paraná & 0,0719 & 0,3108 & 0,0972 & 0,2851 \\
\hline Santa Catarina & 0,0677 & 0,3096 & 0,0976 & 0,2887 \\
\hline Rio Grande do Sul & 0,0667 & 0,2942 & 0,0862 & 0,2628
\end{tabular}

Fonte: Microdados PNAD

Tabela 10_Probabilidade de a mulher estar ocupada, desempregada e inativa, em relação à idade dos filhos - 1995 e 2005 para o Brasil

\begin{tabular}{ll|c|c|c|c|c|c}
\multirow{2}{*}{} & & \multicolumn{2}{c}{ PredPO } & \multicolumn{2}{c}{ PredPD } & \multicolumn{2}{c}{ PredPNEA } \\
\cline { 3 - 8 } & $\mathbf{1 9 9 5}$ & $\mathbf{2 0 0 5}$ & $\mathbf{1 9 9 5}$ & $\mathbf{2 0 0 5}$ & $\mathbf{1 9 9 5}$ & $\mathbf{2 0 0 5}$ \\
\hline TFAM1 & C. 0 filhos & 0,5544 & 0,6026 & 0,0223 & 0,0438 & 0,4233 & 0,3536 \\
\hline TFAM2 & C<14 anos & 0,6267 & 0,6831 & 0,0310 & 0,0621 & 0,3423 & 0,2548 \\
\hline TFAM3 & C>14 anos & 0,5070 & 0,5605 & 0,0387 & 0,0731 & 0,4543 & 0,3664 \\
\hline TFAM6 & M<14anos & 0,7567 & 0,7344 & 0,0575 & 0,0979 & 0,1859 & 0,1677 \\
\hline TFAM7 & M>14anos & 0,5536 & 0,5617 & 0,0427 & 0,0778 & 0,4037 & 0,3605 \\
\hline
\end{tabular}

Fonte: Microdados PNAD, Nota: C - casal, $\mathrm{M}$ - mãe. 
Tabela 11_Efeitos marginais para o logit multinomial em 1995 e 2005

\begin{tabular}{|c|c|c|c|c|c|c|}
\hline \multirow[t]{2}{*}{ Variável } & \multicolumn{2}{|c|}{ Efeito Marginal P.O. } & \multicolumn{2}{|c|}{ Efeito Marginal P.D } & \multicolumn{2}{|c|}{ Efeito Marginal PNEA } \\
\hline & 1995 & 2005 & 1995 & 2005 & 1995 & 2005 \\
\hline Prob (Sit,) & 0,79073335 & 0,78224762 & 0,02060234 & 0,03758109 & 0,18866431 & 0,18017129 \\
\hline Anosestudo & $\begin{array}{r}-0,0174421 \\
(0,00004)\end{array}$ & $\begin{array}{r}-0,0154001 \\
(0,00004)\end{array}$ & $\begin{array}{c}0,0035227 \\
(0,00001)\end{array}$ & $\begin{array}{l}0,0061197 \\
(0,00002)\end{array}$ & $\begin{array}{l}0,0139194 \\
(0,00004)\end{array}$ & $\begin{array}{c}0,0092805 \\
(0,00003)\end{array}$ \\
\hline Anosestudo2 & $\begin{array}{c}0,0014668 \\
(0,00000) \\
\end{array}$ & $\begin{array}{l}0,0014731 \\
(0,00000) \\
\end{array}$ & $\begin{array}{r}-0,000116 \\
(0,00000) \\
\end{array}$ & $\begin{array}{r}-0,0002066 \\
(0,00000) \\
\end{array}$ & $\begin{array}{r}-0,0013508 \\
(0,00000) \\
\end{array}$ & $\begin{array}{r}-0,0012665 \\
(0,00000)\end{array}$ \\
\hline Homem & $\begin{array}{l}0,3161355 \\
(0,00009)\end{array}$ & $\begin{array}{c}0,2548684 \\
(0,00008)\end{array}$ & $\begin{array}{r}-0,0121181 \\
(0,00003)\end{array}$ & $\begin{array}{r}-0,0254619 \\
(0,00003)\end{array}$ & $\begin{array}{r}-0,3040174 \\
(0,00009)\end{array}$ & $\begin{array}{r}-0,2294065 \\
(0,00007)\end{array}$ \\
\hline Filho & $\begin{array}{r}-0,0428767 \\
(0,00018) \\
\end{array}$ & $\begin{array}{r}-0,0780708 \\
(0,00016)\end{array}$ & $\begin{array}{l}0,0091589 \\
(0,00006)\end{array}$ & $\begin{array}{c}0,0129382 \\
(0,00006)\end{array}$ & $\begin{array}{c}0,0337178 \\
(0,00017)\end{array}$ & $\begin{array}{c}0,0651326 \\
(0,00016)\end{array}$ \\
\hline Renda_pc & $\begin{array}{r}-3,53 e-06 \\
(0,00000)\end{array}$ & $\begin{array}{l}0,0000179 \\
(0,00000)\end{array}$ & $\begin{array}{r}-0,0000282 \\
(0,00000)\end{array}$ & $\begin{array}{r}-0,0000337 \\
(0,00000)\end{array}$ & $\begin{array}{c}0,0000318 \\
(0,00000)\end{array}$ & $\begin{array}{l}0,0000158 \\
(0,00000)\end{array}$ \\
\hline Idade & $\begin{array}{l}0,0312156 \\
(0,00002) \\
\end{array}$ & $\begin{array}{l}0,036572 \\
(0,00002) \\
\end{array}$ & $\begin{array}{r}-0,0019735 \\
(0,00001)\end{array}$ & $\begin{array}{r}-0,0037185 \\
(0,00001) \\
\end{array}$ & $\begin{array}{r}-0,0292421 \\
(0,00002)\end{array}$ & $\begin{array}{r}-0,0328534 \\
(0,00002)\end{array}$ \\
\hline Idade 2 & $\begin{array}{r}-0,0004316 \\
(0,00000)\end{array}$ & $\begin{array}{r}-0,0004895 \\
(0,00000)\end{array}$ & $\begin{array}{l}0,0000172 \\
(0,00000) \\
\end{array}$ & $\begin{array}{c}0,0000343 \\
(0,00000)\end{array}$ & $\begin{array}{c}0,0004144 \\
(0,00000)\end{array}$ & $\begin{array}{c}0,0004553 \\
(0,00000) \\
\end{array}$ \\
\hline RM21 PR & $\begin{array}{c}0,0572883 \\
(0,00016)\end{array}$ & $\begin{array}{c}0,0438465 \\
(0,00015)\end{array}$ & $\begin{array}{r}-0,0062445 \\
(0,00005)\end{array}$ & $\begin{array}{r}-0,0139973 \\
(0,00005)\end{array}$ & $\begin{array}{r}-0,0510438 \\
(0,00015)\end{array}$ & $\begin{array}{r}-0,0298492 \\
(0,00014)\end{array}$ \\
\hline RM22 SC & $\begin{array}{c}0,0686532 \\
(0,0002)\end{array}$ & $\begin{array}{c}0,0465285 \\
(0,00019)\end{array}$ & $\begin{array}{r}-0,0097683 \\
(0,00005)\end{array}$ & $\begin{array}{r}-0,0189836 \\
(0,00006)\end{array}$ & $\begin{array}{r}-0,0588849 \\
(0,00019)\end{array}$ & $\begin{array}{r}-0,0275448 \\
(0,00019)\end{array}$ \\
\hline RM23 RGS & $\begin{array}{c}0,0706248 \\
(0,00014)\end{array}$ & $\begin{array}{c}0,0662748 \\
(0,00014)\end{array}$ & $\begin{array}{r}-0,0051629 \\
(0,00005)\end{array}$ & $\begin{array}{r}-0,0133033 \\
(0,00005)\end{array}$ & $\begin{array}{r}-0,0654619 \\
(0,00014)\end{array}$ & $\begin{array}{r}-0,0529715 \\
(0,00013)\end{array}$ \\
\hline TFAM1 & $\begin{array}{r}-0,0015121 \\
(0,00017) \\
\end{array}$ & $\begin{array}{l}0,0143325 \\
(0,00014) \\
\end{array}$ & $\begin{array}{r}-0,001351 \\
(0,00006)\end{array}$ & $\begin{array}{r}-0,0007021 \\
(0,00007) \\
\end{array}$ & $\begin{array}{c}0,0028631 \\
(0,00016)\end{array}$ & $\begin{array}{c}-0,0136304 \\
(0,00012)\end{array}$ \\
\hline TFAM2 & $\begin{array}{r}-0,0523168 \\
(0,00015)\end{array}$ & $\begin{array}{r}-0,022285 \\
(0,00013)\end{array}$ & $\begin{array}{r}-0,001995 \\
(0,00004)\end{array}$ & $\begin{array}{r}-0,0045771 \\
(0,00005)\end{array}$ & $\begin{array}{c}0,0543118 \\
(0,00014)\end{array}$ & $\begin{array}{c}0,0268622 \\
(0,00013)\end{array}$ \\
\hline TFAM3 & $\begin{array}{l}-0,05069 \\
(0,00014) \\
\end{array}$ & $\begin{array}{r}-0,0309027 \\
(0,00012) \\
\end{array}$ & $\begin{array}{l}0,0021583 \\
(0,00004) \\
\end{array}$ & $\begin{array}{c}0,0060575 \\
(0,00005) \\
\end{array}$ & $\begin{array}{r}0,0485317 \\
(0,00013) \\
\end{array}$ & $\begin{array}{c}0,0248452 \\
(0,00011) \\
\end{array}$ \\
\hline TFAM6 & $\begin{array}{c}0,0691298 \\
(0,0002)\end{array}$ & $\begin{array}{l}0,0513096 \\
(0,00019) \\
\end{array}$ & $\begin{array}{c}0,006738 \\
(0,00009)\end{array}$ & $\begin{array}{l}0,0051098 \\
(0,00009)\end{array}$ & $\begin{array}{r}-0,0758678 \\
(0,00018) \\
\end{array}$ & $\begin{array}{r}-0,0564194 \\
(0,00017)\end{array}$ \\
\hline TFAM7 & $\begin{array}{c}0,0090848 \\
(0,00017)\end{array}$ & $\begin{array}{r}-0,0020767 \\
(0,00014)\end{array}$ & $\begin{array}{r}0,004553 \\
(0,00006)\end{array}$ & $\begin{array}{c}0,0101088 \\
(0,00006)\end{array}$ & $\begin{array}{r}-0,0136378 \\
(0,00016)\end{array}$ & $\begin{array}{r}-0,0080322 \\
(0,00013)\end{array}$ \\
\hline
\end{tabular}

Fonte: Microdados PNAD. Desvio padrão entre parênteses. 
capitais e a cidade de São Paulo, para fins de comparação. Esse índice envolve determinar o indicador de desemprego, o indicador de ocupação e o indicador de renda. A cidade que tem a melhor qualidade no mercado de trabalho é Porto Alegre, e, em quinto lugar, Curitiba. Valendo-se do indicador-síntese, o Paraná obteve a pior qualidade de mercado de trabalho entre os Estados da Região Sul do Brasil, seguida do Rio Grande do Sul e de Santa Catarina.

A condição da mulher dentro da família e sua situação no mercado de trabalho indicaram que, se a mulher é casada, a probabilidade de ela estar ocupada é maior se ela tiver filhos com menos de 14 anos. Caso a mulher não seja casada e tenha filhos menores que 14 anos, sua probabilidade de estar ocupado é maior do que se os filhos tivessem mais de 14 anos. Esses resultados apresentam uma tendência contrária, se as mulheres fossem inativas (Tabela 10).

Ao estimar os efeitos marginais do modelo logit multinomial, todos os coeficientes foram significativos. $\mathrm{Na} \mathrm{Ta}$ bela 11, são apresentados os resultados. $\mathrm{A}$ probabilidade de a pessoa estar ocupada em 1995 e 2005 foi de 79,07\% e 78,22\%. Os efeitos marginais significam que, se for homem, essa probabilidade aumenta $31,61 \%$ e $25,48 \%$, respectivamente. Se for filho, ela diminui 4,28\% e 7,80\%, respectivamente. Caso as pessoas estejam nas regióes metropolitanas do Sul do Brasil, haverá aumento da probabilidade de as pessoas estarem ocupadas, mais intensamente em Porto Alegre, tanto em 1995 como em 2005.

Ao se analisar a relação de situação no mercado de trabalho e filhos, verifica-se que, para um casal sem filhos (TFAM1), haverá aumento na probabilidade de estar ocupado em 2005; e, para um casal com filhos menores e maiores de 14 anos (TFAM2, TFAM3), haverá diminuição na probabilidade de estar ocupado. Já para o caso de mães com filhos menores e maiores que 14 anos (TFAM6, TFAM7), haverá aumento na probabilidade de estar ocupado, principalmente para o primeiro caso. Tal resultado foi o esperado, uma vez que esse tipo de família é composto da mãe e dos filhos, em que a principal fonte de renda é proveniente da mãe.

\section{6_Considerações finais}

Ao se examinar a posição dos indivíduos no mercado de trabalho (ocupado, desempregado e inativo - fora do mercado de trabalho), em 1995 e 2005, verificou-se maior participação da mulher no mercado, cuja taxa de inatividade pas- 
sou de $44,7 \%$ para $39,1 \%$. No Brasil, essa taxa foi menor na Região Sul, comparativamente com o Brasil.

No que diz respeito à taxa de desemprego, houve aumento nesse período, principalmente entre as mulheres, passando de $6,4 \%$ para $10,5 \%$. No Brasil, essa taxa foi menor na Região Sul, comparativamente com o Brasil. Verificou-se ainda uma relação decrescente entre a taxa de inatividade e os anos de estudos.

Quanto à relação entre taxa de desemprego e anos de estudo, verificouse ser essa positiva decrescente com um ponto de máximo na faixa de 8 a 10 anos de estudos. A relação entre taxa de inatividade e idade é negativa crescente com um ponto de mínimo na faixa de 31 a 45 anos. A taxa de desemprego e idade apresenta relação negativa.

Com base no modelo econométrico proposto, pôde-se verificar que existe relação positiva entre probabilidade de estar ocupado e anos de estudo, sem diferença entre 1995 e 2005. Já no que concerne à probabilidade de estar desempregado e anos de estudo, observouse relação positiva decrescente com um ponto de máximo localizado aproximadamente em 10 anos. É possível observar que, para um mesmo ano de estudo, a probabilidade de estar desempregado foi maior em 2005.
A relação entre a probabilidade de estar inativo e anos de estudos apresentou-se negativa, não mostrando diferença em 1995 e 2005. Já entre a possibilidade de estar ocupado e idade evidenciou ser positiva decrescente com um ponto de máximo aproximadamente com a idade de 40 anos, não havendo diferença entre os anos de 1995 e 2005. A relação entre a probabilidade de estar desempregado e idade apresentou-se decrescente, com um ponto de máximo com a idade de 16 anos.

Esses resultados confirmam a situação atual do mercado de trabalho, com problemas de colocação dos jovens e a dificuldade da realocação no mercado de trabalho para as pessoas acima dos 40 anos. Isso é novamente confirmado pela relação entre a probabilidade de estar inativo e idade, com a presença de um ponto de mínimo por volta dos 40 anos.

Tais resultados são encontrados na literatura e têm impacto sobre diretrizes nas políticas públicas, pois se torna cada vez mais necessário criar meios no intuito de que as pessoas mais qualificadas e com idade mais elevadas permaneçam no mercado de trabalho, o que proporcionaria vantagens para a empresa, para o trabalhador e para o governo. Dessa forma, haverá diminuição sobre as contas da previdência, já que, à 
medida que aumenta a expectativa de vida e diminui a taxa de natalidade, se espera que haja uma alteração na razão entre o número de pessoas que contribuem com a previdência e o número de pessoas aposentadas.

Ao se verificar a diferença entre os Estados da Região Sul no que diz respeito à probabilidade de estar ocupado, observa-se que essa diminuiu de 1995 a 2005. Tal diminuição foi mais intensa na Região Sul, comparativamente com o Brasil, e a análise por gênero evidencia que, de 1995 a 2005, no Brasil, a chance de estar ocupado aumentou para a mulher e diminuiu para o homem.

Por sua vez, a condição da mulher na família e a probabilidade de estar ocupada é maior se a mulher for mãe, não casada, com filhos menores de 14 anos $(75,67 \%)$, essa probabilidade permaneceu aproximadamente a mesma para os anos de 1995 e 2005. Caso os filhos tivessem mais de 14 anos, essa cairia para o valor de $55,36 \%$. Talvez isso ocorra pelo fato de que, agora, o filho poderá colaborar com a renda familiar. Independentemente da condição da mulher na família, verifica-se que houve diminuição da probabilidade de estar inativo em 1995 e 2005, indicando aumento da participação da mulher no mercado de trabalho, nesse período. 


\section{Referências bibliográficas}

\section{BUKOWSHI, M.;}

LEWANDOWSKI, P. Transitions

from unemployment in Poland: A multinomial logit analysis. Warsaw School of Economics - Institute for Structural Research. Nov. 2005. 44p

CAMARGO, J. M. Estabilização, emprego e restriçáa externa. In: VELLOSO, J. P. R.

Brasil: Desafios de um país em transformação, Fórum Nacional. Rio de Janeiro, Cidade: José Olympio Editora, 1997. p. 248-270.

CAMARGO, J. M.; NERI, M.; REIS, M. C. Emprego e produtividade no Brasil na década de 1990. In: BAUMANN, R. Brasil uma década em transformação. Rio de Janeiro Cidade: Campus, p. 255-288, 2000.

CAHUC, P.; ZYLBERBERG, A. Labor Economics, MIT Press, 2004. 841p.

CORSINI, L.; GUERRAZZI, M. The transition form temporary to permanent employment: Evidence from Tuscany. Labour, v. 21, n. 2, p. 303-332, 2007
CURI, A. Z.; MENEZESFILHO, N. A. O mercado de trabalho brasileiro é segmentado? Alterações no perfil da informalidade e nos diferenciais de salários nas décadas de 1980 e 1990. Estudos Econômicos,

Sáo Paulo, v. 36, n. 4, p. $867-$ 899, 2006.

DIAS, M.; MATA, J. Transição no mercado de trabalho. Boletim Econômico. Banco de Portugal. mar. 1997. 13p.

EHRENBERG, R. G.; SMITH,

R. S. A moderna economia do trabalho, teoria e politica pública. 5. ed. Makron Books, 2000. 793p

FERNANDES, R.; PICCHETTI,

P. Uma análise da estrutura do desemprego e da inatividade no Brasil metropolitano. Pesq. Plan. Econ. Rio de Janeiro, v. 29, n. 1, abr. 1999.

GRUBER, R. R.; CAMPOS, S. M.; LIMA, J. F. O mercado de trabalho nas cidades médias da Região Sul do Brasil: Aplicação do índice de Saboia. Ensaios FEE, Porto Alegre, v. 30, n. 1, p. 135 164, maio 2009.
HAUSMAN, J.; MACFADDEN,

D. Specification tests for the Multinomial Logit Model.

Econometrica, v. 52, n. 5, p. 12191240, 1984

POCHMANN, M. A batalha pelo primeiro emprego. Sáo Paulo Cidade: Publisher Brasil, 2000. 95p.

OLLIKAINEN, V. Gender differences in transitions from unemployment: Micro evidence from Filand. Labour, v. 20, n. 1, p. 159-198, 2006.

RAMOS, L.; REIS, J. G. A.

Emprego no Brasil nos anos 90. IPEA, Texto de Discussão n. 468, Rio de Janeiro, mar. 1997. 28p.

SCHMITT, C.; RIBEIRO, E.

P. Participação feminina no mercado de trabalho e o "efeito trabalhador adicional" em Porto Alegre. Ensaios FEE, Porto Alegre, v. 25 , n. 1, p. 145-170, abr. 2004.

VOICU, A. Labor force participation dynamics in the Romanian labor market. IZA, Bonn, Germany, Apr. 13, 2002.37p.
WOOLDRIDGE, J. M.

Econometric analysis of cross section and Panel Data. MIT Press, 2002. 752p

\section{E-mail de contato dos autores}

avsampaio@ufpr.br 


\section{TESTE IIA}

\section{ANO 1995}

Hausman tests of IIA assumption

Ho: Odds(Outcome-J vs Outcome-K) are independent of other alternatives

\begin{tabular}{c|c|c|c|c}
\hline Omitted & chi2 & df & P>chi2 & evidence \\
\hline 2_(PD) & $-4.4 \mathrm{e}+04$ & 14 & 1.000 & for Ho \\
\hline 3_(PNEA) & $-1.7 \mathrm{e}+05$ & 15 & 1.000 & for Ho \\
\hline 1_(PO) & $-2.2 \mathrm{e}+06$ & 15 & 1.000 & for Ho \\
\hline
\end{tabular}

\section{ANO 2005}

\section{Hausman tests of IIA assumption}

Ho: Odds(Outcome-J vs Outcome-K) are independent of other alternatives

\begin{tabular}{c|c|c|c|c}
\hline Omitted & chi2 & df & P>chi2 & evidence \\
\hline 2_(PD) & $-8.7 \mathrm{e}+04$ & 14 & 1.000 & for Ho \\
\hline 3_(PNEA) & $-1.7 \mathrm{e}+05$ & 15 & 1.000 & for Ho \\
\hline 1_(PO) & $-8.6 \mathrm{e}+04$ & 15 & 1.000 & for Ho \\
\hline
\end{tabular}




\section{ANO 1995}

Iteration 5: log likelihood $=\mathbf{- 5 1 5 9 9 3 8 0}$

Multinomial logistic regression

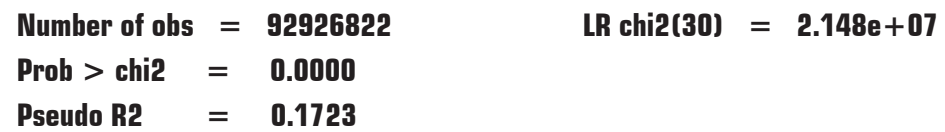

Pseudo R2 = 0.1723

(continua)

Log likelihood $=-51599380$

\begin{tabular}{|c|c|c|c|c|c|c|}
\hline SIT & Coef & Std. Err. & $\mathbf{z}$ & $\mathbf{P}>|z|$ & \multicolumn{2}{|c|}{ [95\% Coef. Interval] } \\
\hline \multicolumn{7}{|l|}{ PD } \\
\hline Anoestudo & 0.1930433 & 0.0006758 & 285.66 & 0.000 & 0.1917188 & 0.1943678 \\
\hline Anoestudo2 & -0.0074872 & 0.0000407 & -183.98 & 0.000 & -0.007567 & -0.0074075 \\
\hline Homem & -1.059409 & 0.0014027 & -755.29 & 0.000 & -1.062159 & -1.05666 \\
\hline Filho & 0.4524987 & 0.0024149 & 187.38 & 0.000 & 0.4477656 & 0.4572317 \\
\hline Renda_pc & -0.0013665 & $4.00 e-06$ & -341.70 & 0.000 & -0.0013743 & -0.0013587 \\
\hline Idade & -0.1352674 & 0.0003302 & -409.70 & 0.000 & -0.1359145 & -0.1346202 \\
\hline Idade2 & 0.0013786 & $4.48 \mathrm{e}-06$ & 307.87 & 0.000 & 0.0013698 & 0.0013874 \\
\hline RM21-PR & -0.4227545 & 0.0031061 & -136.11 & 0.000 & -0.4288422 & -0.4166667 \\
\hline RM22-SC & -0.7083518 & 0.0047831 & -148.09 & 0.000 & -0.7177265 & -0.6989771 \\
\hline RM23-RGS & -0.3687494 & 0.0029185 & -126.35 & 0.000 & -0.3744696 & -0.3630292 \\
\hline TFAM1 & -0.0654182 & 0.0031026 & -21.09 & 0.000 & -0.0714991 & -0.0593373 \\
\hline TFAM2 & -0.0318371 & 0.0022455 & -14.18 & 0.000 & -0.0362382 & -0.027436 \\
\hline TFAM3 & 0.1671831 & 0.001857 & 90.03 & 0.000 & 0.1635435 & 0.1708227 \\
\hline TFAM6 & 0.201164 & 0.0032599 & 61.71 & 0.000 & 0.1947746 & 0.2075534 \\
\hline TFAM7 & 0.1911348 & 0.0023365 & 81.80 & 0.000 & 0.1865553 & 0.1957143 \\
\hline cons & -0.90757 & 0.006541 & -138.75 & 0.000 & -0.92039 & -0.89474993 \\
\hline
\end{tabular}


(conclusão)

\begin{tabular}{|c|c|c|c|c|c|c|}
\hline SIT & Coef & Std. Err. & $\mathbf{z}$ & $\mathbf{P}>\mid z$ & \multicolumn{2}{|c|}{ [95\% Coef. Interval] } \\
\hline \multicolumn{7}{|l|}{ PNEA } \\
\hline Anoestudo & 0.0958365 & 0.000253 & 378.85 & 0.000 & 0.0953407 & 0.0963323 \\
\hline Anoestudo2 & -0.0090147 & 0.0000163 & -552.12 & 0.000 & -0.0090467 & -0.0089827 \\
\hline Homem & -2.038333 & 0.0006519 & -3126.94 & 0.000 & -2.039611 & -2.037055 \\
\hline Filho & 0.2257727 & 0.0010718 & 210.64 & 0.000 & 0.223672 & 0.2278735 \\
\hline Renda_pc & 0.0001729 & $7.47 \mathrm{e}-07$ & 231.52 & 0.000 & 0.0001714 & 0.0001743 \\
\hline Idade & -0.1944723 & 0.0001211 & -1605.59 & 0.000 & -0.1947097 & -0.1942349 \\
\hline Idade2 & 0.0027423 & $1.43 e-06$ & 1917.04 & 0.000 & 0.0027395 & 0.0027451 \\
\hline RM21-PR & -0.3793029 & 0.0012352 & -307.09 & 0.000 & -0.3817238 & -0.376882 \\
\hline RM22-SC & -0.4523925 & 0.0016467 & -274.73 & 0.000 & -0.4556198 & -0.4491651 \\
\hline RM23-RGS & -0.4985443 & 0.0011927 & -418.01 & 0.000 & -0.5008819 & -0.4962067 \\
\hline TFAM1 & 0.0169991 & 0.0010324 & 16.47 & 0.000 & 0.0149756 & 0.0190226 \\
\hline TFAM2 & 0.3382784 & 0.0008524 & 396.84 & 0.000 & 0.3366077 & 0.3399492 \\
\hline TFAM3 & 0.3049845 & 0.0007946 & 383.84 & 0.000 & 0.3034272 & 0.3065418 \\
\hline TFAM6 & -0.5889187 & 0.0017503 & -336.48 & 0.000 & -0.5923491 & -0.5854882 \\
\hline TFAM7 & -0.0860183 & 0.0011229 & -76.61 & 0.000 & -0.0882191 & -0.0838175 \\
\hline _cons & 2.201016 & 0.0027085 & 812.64 & 0.000 & 2.195708 & 2.206325 \\
\hline
\end{tabular}

(SIT $==\mathrm{PO}$ is the base outcome) 


\section{ANO 2005}

Iteration 5: $\quad$ log likelihood $=\mathbf{- 7 3 7 9 8 7 1 8}$

Multinomial logistic regression

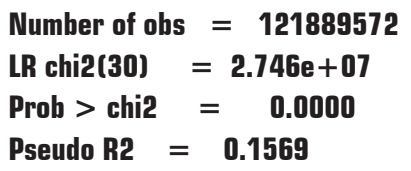

\begin{tabular}{|c|c|c|c|c|c|c|}
\hline SIT & Coef & Std. Err. & $\mathbf{Z}$ & $\mathbf{p}>\mid z$ & \multicolumn{2}{|c|}{ [95\% Coef. Interval] } \\
\hline \multicolumn{7}{|l|}{ PD } \\
\hline Anoesdudo & 0.1825259 & 0.000492 & 370.96 & 0.000 & 0.1815615 & 0.1834903 \\
\hline Anoestudo2 & -0.0073799 & 0.0000279 & -264.23 & 0.000 & -0.0074346 & -0.0073251 \\
\hline Homem & -1.044719 & 0.0009267 & -1127.34 & 0.000 & -1.046535 & -1.042902 \\
\hline Filho & 0.4193058 & 0.0015325 & 273.61 & 0.000 & 0.4163021 & 0.4223094 \\
\hline Renda_pc & -0.0009189 & $1.52 \mathrm{e}-06$ & -604.59 & 0.000 & -0.0009219 & -0.0009159 \\
\hline Idade & -0.1456996 & 0.0002136 & -681.96 & 0.000 & -0.1461184 & -0.1452809 \\
\hline Idade2 & 0.0015373 & $2.86 e-06$ & 538.27 & 0.000 & 0.0015317 & 0.0015429 \\
\hline RM21-PR & -0.5058708 & 0.0021974 & -230.21 & 0.000 & -0.5101777 & -0.5015639 \\
\hline RM22-SC & -0.7393497 & 0.0032561 & -227.07 & 0.000 & -0.7457316 & -0.7329679 \\
\hline RM23-RGS & -0.5052978 & 0.0021527 & -234.72 & 0.000 & -0.5095171 & -0.5010784 \\
\hline TFAM1 & -0.0370144 & 0.0018574 & -19.93 & 0.000 & -0.0406549 & -0.033374 \\
\hline TFAM2 & -0.0972477 & 0.0014934 & -65.12 & 0.000 & -0.1001747 & -0.0943207 \\
\hline TFAM3 & 0.1950322 & 0.001235 & 157.92 & 0.000 & 0.1926117 & 0.1974527 \\
\hline TFAM6 & 0.0643563 & 0.0021221 & 30.33 & 0.000 & 0.0601971 & 0.0685155 \\
\hline TFAM7 & 0.2462337 & 0.001486 & 165.70 & 0.000 & 0.2433212 & 0.2491462 \\
\hline _cons & -0.0409992 & 0.0045563 & -9.00 & 0.000 & -0.0499294 & -0.032069 \\
\hline
\end{tabular}




\begin{tabular}{|c|c|c|c|c|c|c|}
\hline SIT & Coef & Std. Err. & $\mathbf{Z}$ & $\mathbf{p}>\mid z$ & \multicolumn{2}{|c|}{ [95\% Coef. Interval] } \\
\hline \multicolumn{7}{|l|}{ PNEA } \\
\hline Anoestudo & 0.0711962 & 0.0002334 & 0.0002334 & 0.000 & 0.0707388 & 0.0716536 \\
\hline Anoestudo2 & -0.0089125 & 0.0000144 & -617.78 & 0.000 & -0.0089407 & -0.0088842 \\
\hline Homem & -1.617125 & 0.0005531 & -2923.99 & 0.000 & -1.618209 & -1.616041 \\
\hline Filho & 0.4337613 & 0.000936 & 463.42 & 0.000 & 0.4319267 & 0.4355958 \\
\hline Renda_pc & 0.0000646 & $3.35 e-07$ & 192.80 & 0.000 & 0.0000639 & 0.0000652 \\
\hline Idade & -0.229098 & 0.0001077 & -2126.31 & 0.000 & -0.2293092 & -0.2288868 \\
\hline Idade2 & 0.0031526 & $1.26 \mathrm{e}-06$ & 2492.52 & 0.000 & 0.0031502 & 0.0031551 \\
\hline RM21-PR & -0.2339054 & 0.0011018 & -212.29 & 0.000 & -0.236065 & -0.2317459 \\
\hline RM22-SC & -0.2229052 & 0.0014277 & -156.13 & 0.000 & -0.2257035 & -0.2201069 \\
\hline RM23-RGS & -0.4217695 & 0.0011033 & -382.27 & 0.000 & -0.4239319 & -0.419607 \\
\hline TFAM1 & -0.0960626 & 0.0008797 & -109.20 & 0.000 & -0.0977867 & -0.0943384 \\
\hline TFAM2 & 0.1721074 & 0.0008272 & 208.07 & 0.000 & 0.1704862 & 0.1737286 \\
\hline TFAM3 & 0.1733596 & 0.0006968 & 248.78 & 0.000 & 0.1719938 & 0.1747254 \\
\hline TFAM6 & -0.4339616 & 0.0015435 & -281.15 & 0.000 & -0.4369868 & -0.4309363 \\
\hline TFAM7 & -0.0427371 & -0.0427371 & -46.22 & 0.000 & -0.0445493 & -0.0409249 \\
\hline _cons & 2.863804 & 0.0024855 & 1152.21 & 0.000 & 2.858932 & 2.868675 \\
\hline
\end{tabular}

(SIT $==$ PO is the base outcome) 
